\title{
Relative bioavailability of salbutamol to the lung following inhalation using metered dose inhalation methods and spacer devices
}

\author{
M Hindle*, H Chrystyn
}

\begin{abstract}
Background - Inhalation aids do not require coordination between actuation of a metered dose inhaler (MDI) with inspiration and reduce oropharyngeal impaction. The delivery of salbutamol to the lung and systemic availability following inhalation with three commonly used spacers and an open mouth technique have been evaluated using a simple noninvasive technique based on urinary excretion 30 minutes and 24 hours after the dose.
\end{abstract}

Methods - Ten healthy subjects inhaled, on randomised study days, $4 \times 100 \mu \mathrm{g}$ from a Ventolin MDI and, subsequently, with the aid of a Volumatic, Bricanyl Spacer, and Nebuhaler spacer device. In addition, an open mouth inhaler technique was evaluated. Urine samples were collected 0-30 minutes and 0.5-24 hours after inhalation. From these samples the relative bioavailability to the lung (urinary salbutamol excretion 30 minutes after dosing) and the systemic bioavailability of the dose ( 24 hour urinary excretion of salbutamol and its metabolite) for each inhalation method was obtained.

Results - The mean (SD) urinary excretion of salbutamol 30 minutes after inhalation using the MDI alone and with the Volumatic, Bricanyl Spacer, Nebuhaler, and open mouth technique was 2.83 (0.78)\%, 3.37 (0.69)\%, 4.09 (0.91)\%, 4.34 $(1.60) \%$, and $3.49(0.98) \%$, respectively, expressed as a percentage of the nominal dose. The Nebuhaler and Bricanyl Spacer spacer devices were found to increase the relative bioavailability of salbutamol to the lung compared with the MDI alone. Compared with the MDI the inhalation aid increases were much greater than the intra-individual variability of the urinary excretion method. In 11 individuals who each repeated the same inhalation procedure on four separate occasions, the mean (SD) coefficient of variation was $8.24(2 \cdot 36) \%$. The mean (SD) 24 hour urinary excretion of salbutamol and its metabolites was $26 \cdot 6$ $(6.79), 27.0(7.95)$, and $55.6(9.74) \%$ of the salbutamol dose for the Volumatic, Nebuhaler, and MDI, respectively. Similar values following the open mouth method and Bricanyl Spacer were 48.9 $(10.97) \%$ and $43.8(11.57) \%$. These values, representing the systemic availability of the inhaled dose, were lower when inhaling with the aid of the Volumatic and Nebuhaler than inhalation from the MDI alone.

Conclusions - Spacer devices improve pulmonary bioavailability of salbutamol and reduce the systemically available dose.

\section{(Thorax 1994;49:549-553)}

The metered dose inhaler (MDI) is the device of choice for the delivery of inhaled drugs to their sites of action within the lungs. However, a large proportion of patients fail to use their MDIs correctly. ${ }^{12}$ The most common error is poor coordination between the beginning of inspiration and actuation of the device. It has been reported that $51 \%$ of patients have difficulty with coordination. ${ }^{3}$ An open mouth inhaler technique, holding the inhaler approximately $5 \mathrm{~cm}$ in front of an open mouth, has been suggested as an alternative to the conventional closed mouth inhalation technique. ${ }^{4}$ The gap between the inhaler and an open mouth creates a spacer effect, thereby decreasing impaction at the back of the throat and increasing pulmonary deposition. Furthermore, this gap ensures that coordination of inspiration and actuation of the device is less critical.

A large proportion (about $90 \%$ ) of the dose released from an MDI impacts in the mouth and is swallowed which may cause oral candidiasis and dysphonia, ${ }^{5}$ and systemic (adrenal suppression $)^{6}$ adverse effects, respectively, following corticosteroid inhalation. The incidence of these is reduced by large volume reservoir spacers. A recent editorial in the British Medical fournal has advocated the use of large volume plastic spacers by all patients receiving inhaled medication from an $\mathrm{MDI}{ }^{7}$ Inhalation from a static aerosol cloud, from within these devices, reduces particle velocity during inspiration thereby limiting oropharyngeal impaction and systemic absorption. These spacers also overcome the problems of poor coordination and enable an increase in the proportion of the dose delivered to the therapeutically active sites within the lungs. ${ }^{89}$

We have shown that the percentage (amount) of an inhaled dose of salbutamol recovered in a urine sample taken 30 minutes after inhalation is an index of the relative amounts of drug deposited in the respiratory 
tract - that is, the relative bioavailability of salbutamol to the lung. ${ }^{10}$ Measurement of the 24 hour urinary recovery of salbutamol and its sulphate conjugate metabolite allows an estimate of the total systemic availability of the inhaled dose. ${ }^{10}$ Using this method we have shown how improvements of the inhalation technique increase lung deposition. ${ }^{11}$ This method of urinary excretion has now been used to evaluate the potential of inhalation aids (and an open mouth technique) to increase pulmonary drug deposition and to reduce oral absorption. To show that any changes represent real differences the reproducibility of the urinary salbutamol method following inhalation from an MDI is reported.

\section{Methods}

Ten healthy subjects, thoroughly trained and experienced with inhalation methods, gave written informed consent (University of Bradford ethics committee approval obtained) to inhale salbutamol from an MDI (Ventolin, Allen and Hanburys Ltd, UK) and then, on different study days, with the aid of a Volumatic (Allen and Hanburys), Bricanyl Spacer (Astra Pharmaceuticals, Sweden), and Nebuhaler (Astra Pharmaceuticals). The standard Ventolin canister was used with each of the inhalation aids. An open mouth inhaler technique, ${ }^{4}$ using the Ventolin MDI, was also evaluated. On each occasion subjects exhaled to residual volume before a slow deep inhalation over a period of 5-10 seconds, followed by a 10 second breath hold. ${ }^{11}$ This manoeuvre was repeated four times $(4 \times 100 \mu \mathrm{g}$ doses from the MDI) with an interval of 30 seconds between each dose. Each method was assessed on a separate day, with seven day washout intervals, and the order of administration was randomised.

Subjects emptied their bladders immediately before the doses and then urine samples were collected at 30 minutes and subsequently pooled until 24 hours after the dose. The volume of urine passed was recorded and $\mathrm{pH}$ measured. Urine samples were stored at $-20^{\circ} \mathrm{C}$ before analysis. A previously validated sensitive high performance liquid chromatography (HPLC) method was used to measure urine concentrations of salbutamol and its metabolite, the sulphate ester conjugate. ${ }^{10} \mathrm{Im}$ mediately after inhalation of the four doses each spacer was washed with $6 \mathrm{ml}$ methanol

Table 1 Fate of salbutamol following inhalation from a metered dose inhaler (MDI) using a standard and open mouth technique and with the aid of a Volumatic, Bricanyl Spacer, and Nebuhaler (values are mean (SD) expressed as a \% of the salbutamol Spacer,
dose)

\begin{tabular}{lccccc}
\hline & $M D I$ & $\begin{array}{l}\text { Open } \\
\text { mouth }\end{array}$ & Volumatic & $\begin{array}{l}\text { Bricanyl } \\
\text { Spacer }\end{array}$ & Nebuhaler \\
\hline $\begin{array}{l}\text { Urinary unchanged } \\
\text { salbutamol excretion }\end{array}$ & $\begin{array}{c}2.83 \\
\text { 30 minutes after dose }\end{array}$ & $\begin{array}{c}3.49 \\
(0.98)\end{array}$ & $\begin{array}{c}3.37 \\
(0.69)\end{array}$ & $\begin{array}{c}4.09 \\
(0.91)\end{array}$ & $\begin{array}{c}4.34 \\
(1.60)\end{array}$ \\
$\begin{array}{l}\text { Total urinary recovery } \\
\text { (salbutamol + metabolite) }\end{array}$ & $\begin{array}{l}55.57 \\
\text { 24 hours after dose }\end{array}$ & $\begin{array}{l}48 \cdot 86 \\
(10.97)\end{array}$ & $\begin{array}{l}26.55 \\
(6.79)\end{array}$ & $\begin{array}{l}43.75 \\
(11.57)\end{array}$ & $\begin{array}{l}27.00 \\
(7.95)\end{array}$ \\
$\begin{array}{l}\text { Salbutamol recovered in } \\
\text { device }\end{array}$ & $\begin{array}{l}26.73 \\
(2.45)\end{array}$ & N/A & $\begin{array}{l}54 \cdot 7 \\
(7.44)\end{array}$ & $\begin{array}{l}27.8 \\
(9.40)\end{array}$ & $\begin{array}{l}46.4 \\
(12.08)\end{array}$ \\
\hline
\end{tabular}

N/A = Not applicable followed by distilled water. These washings were collected and made up to $100 \mathrm{ml}$ in a volumetric flask and measured by the same method as the urine samples.

The intrasubject reproducibility of the urinary method was assessed in 11 healthy volunteers (eight from the above group). Following inhalation of $4 \times 100 \mu \mathrm{g}$ salbutamol doses from a Ventolin MDI using a standardised inhaler technique $^{11}$ urine samples were provided at 0-30 minutes and 0.5-24 hours after the dose. Urine samples were analysed as above. Each individual repeated this procedure on three other occasions (four in total) with suitable washout periods in between. From the four sets of results for each individual the average amount excreted in the urine was calculated, together with the coefficient of variation. From these individual average values and coefficients of variation the mean (SD) for the 11 subjects was calculated for the 0-30 minute and 0-24 hour samples.

\section{DATA ANALYSIS}

Statistical comparisons were made using the Wilcoxon signed rank test together with the median difference and $95 \%$ confidence intervals.

\section{Results}

Ten healthy subjects (five women) with mean (SD) age, weight, and height of $29.3(7 \cdot 3)$ years, $68.3(10.7) \mathrm{kg}$, and $1.71(0.12) \mathrm{m}$, respectively, completed the spacer study. Their mean (SD) $\mathrm{FEV}_{1}$ was $103.4(9.3) \%$ of the predicted value. The $\mathrm{pH}$ of all urine samples was between 4.5 and 6.5 .

An increase in the urinary salbutamol excretion 30 minutes after dosing was seen when the MDI was used with the aid of a Volumatic, Nebuhaler, and Bricanyl Spacer, and with the open mouth method (table 1, figure). Table 2 reveals that the increases for the Volumatic and open mouth method compared with the MDI failed to reach statistical significance, whereas the Bricanyl Spacer and Nebuhaler significantly $(p<0.05)$ increased the urinary salbutamol excretion 30 minutes after inhalation. All other comparisons between 30 minute urinary excretion values were not statistically significant.

Based on the 30 minute urinary salbutamol data in table 1 the mean percentage increases for the relative bioavailability of salbutamol to the lung compared with the MDI were $19 \cdot 1 \%$, $23.3 \%, 44.5 \%$, and $53.4 \%$ for the Volumatic, open mouth method, Bricanyl Spacer, and Nebuhaler, respectively.

The systemic availability of the dose (24 hour urinary elimination of salbutamol and its sulphate ester metabolite) following inhalation with the aid of the Volumatic and Nebuhaler was lower than that from the MDI alone and the open mouth method (table 1). Statistical analysis showed that all these reductions were significant $(p<0.01)$. The Bricanyl Spacer also decreased the total systemic bioavailability $(43.8 \%)$, although this reduction, when com- 

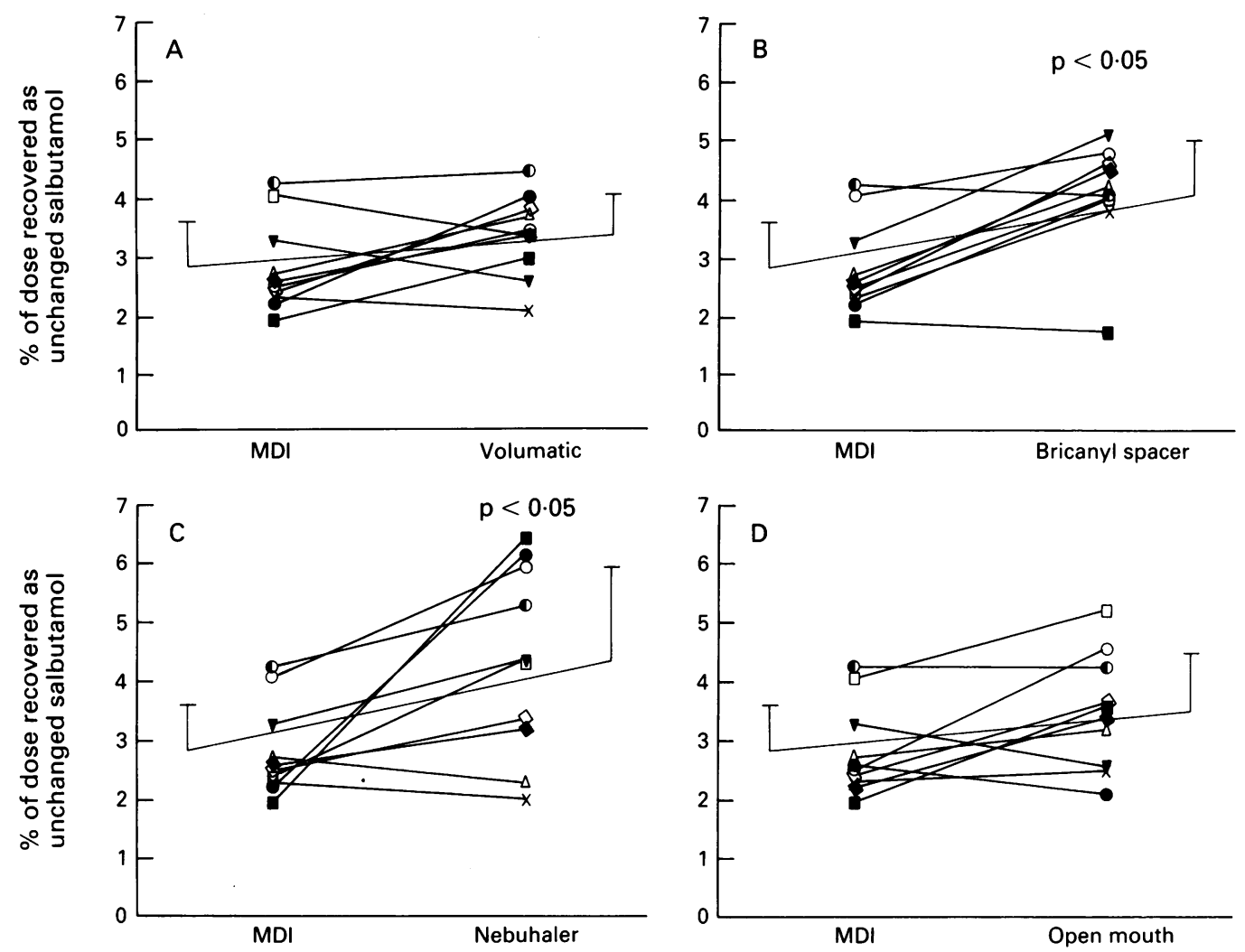

Individual values of urinary salbutamol recovery 0.5 hours after inhalation with the MDI alone compared with (A) Volumatic, (B) Bricanyl Spacer, (C) Nebuhaler, and (D) open mouth technique.

pared with that from the MDI, was less significant $(p<0.05)$. The amount of salbutamol remaining in each spacer device after the inhalations is shown in table 1.

The reproducibility of the urinary salbutamol method for the $0-30$ minute and 0-24 hour after inhalation urine collections in 11 individuals, following $4 \times 100 \mu \mathrm{g}$ salbutamol $\mathrm{MDI}$ doses on four separate occasions using a standardised MDI inhalation technique, is shown in table 3.

Table 2 Statistical comparison of the 30 minute urinary salbutamol excretion compared with the MDI (all values expressed as $a \%$ of the inhaled dose)

\begin{tabular}{llll}
\hline Device comparison & Median difference & $95 \%$ Confidence interval & $p$ \\
\hline Volumatic & 0.58 & $-0.01,1.19$ & NS \\
Nebuhaler & 1.50 & $0.69,1.84$ & $<0.05$ \\
Bricanyl Spacer & 1.37 & $0.32,2.76$ & $<0.05$ \\
Open mouth & 0.65 & $-0.02,1.38$ & NS \\
\hline
\end{tabular}

Table 3 Reproducibility of the urinary excretion method ( $n=4$ for each individual)

\begin{tabular}{|c|c|c|c|c|}
\hline \multirow[b]{2}{*}{ Subject no. } & \multicolumn{2}{|c|}{$\begin{array}{l}\text { Mean inhaled dose excreted } \\
\text { in the urine }(\%)\end{array}$} & \multicolumn{2}{|c|}{ Coefficient of variation (\%) } \\
\hline & $0-30$ minutes & $0-24$ hours & $0-30$ minutes & $0-24$ hours \\
\hline $\begin{array}{r}1 \\
2 \\
3 \\
4 \\
5 \\
6 \\
7 \\
8 \\
9 \\
10 \\
11\end{array}$ & $\begin{array}{l}1.96 \\
3.01 \\
1.70 \\
2.48 \\
2.16 \\
2.34 \\
4.07 \\
2.69 \\
2.55 \\
2.55 \\
3.69\end{array}$ & $\begin{array}{l}62.35 \\
48 \cdot 35 \\
49 \cdot 68 \\
55 \cdot 18 \\
49 \cdot 78 \\
42.95 \\
49.93 \\
57.05 \\
51.63 \\
43.40 \\
64.83\end{array}$ & $\begin{array}{r}9 \cdot 41 \\
7 \cdot 23 \\
13 \cdot 53 \\
8 \cdot 99 \\
9 \cdot 80 \\
8 \cdot 62 \\
8 \cdot 38 \\
6 \cdot 48 \\
7 \cdot 83 \\
5 \cdot 10 \\
5 \cdot 23\end{array}$ & $\begin{array}{r}4.59 \\
12.57 \\
5.72 \\
11.23 \\
9.84 \\
10.38 \\
6.95 \\
5.83 \\
8.61 \\
7.64 \\
6.99\end{array}$ \\
\hline $\begin{array}{l}\text { Mean } \\
\text { SD }\end{array}$ & $\begin{array}{l}2 \cdot 66 \\
0 \cdot 71\end{array}$ & $\begin{array}{r}52 \cdot 28 \\
7 \cdot 00\end{array}$ & $\begin{array}{l}8 \cdot 24 \\
2 \cdot 36\end{array}$ & $\begin{array}{l}8 \cdot 21 \\
2 \cdot 53\end{array}$ \\
\hline
\end{tabular}

\section{Discussion}

The reproducibility of the $0-30$ minute and 0-24 hour urinary excretion methods revealed coefficients of variation of less than $10 \%$. These values represent the relative amount absorbed through the lungs, and the combined pulmonary and oral route, ${ }^{10}$ respectively. Both measurements will include human variability in inhalation technique and urinary excretion, together with variation in dosage delivery from an $\mathrm{MDI}^{12}$ and the salbutamol assay. ${ }^{10}$ Since all the individuals were highly trained and experienced in inhalation techniques, the variability resulting from this would be negligible. Owing to the relatively small overall coefficients of variation, any large differences or trends between inhalation methods and the MDI values will, therefore, represent real differences.

The two large volume $(750 \mathrm{ml})$ plastic spacers investigated (Volumatic and Nebuhaler) significantly $(\mathrm{p}<0.01)$ reduced the systemic availability of the dose. Of the dose fired, $46.4 \%$ remained in the Nebuhaler after inhalation, which is similar to previous reports of $58 \%$ by Vidgren $e t$ al and $56 \%$ by Newman $e t$ $a l,{ }^{9}$ and $54.7 \%$ of the dose was left in the Volumatic, which is slightly larger than $44.8 \%$ and $37.9 \%$ following inhalation by volunteers and asthmatics, respectively, reported in a study using salbutamol labelled with technetium-99m. ${ }^{13}$

The Nebuhaler was found to be the most efficient inhalation aid of those evaluated, despite using a Ventolin MDI canister instead of the Bricanyl MDI (Astra Pharmaceuticals) for which it is designed. There was a significant 
$(p<0.05)$ increase in the relative bioavailability of salbutamol in the lung when the Nebuhaler was used with the Ventolin MDI compared with the MDI alone. The 30 minute urinary excretion (corresponding to the relative lung bioavailability) of salbutamol following Ventolin MDI use with the Nebuhaler was $28.8 \%$ higher than that of the Volumatic, but the differences did not reach statistical significance because of the low numbers. This improvement may result from a favoured alteration of the aerosol cloud from the Ventolin MDI by the Nebuhaler spray nozzle, or from the more aerodynamic shape of the Nebuhaler. The volunteers who used these inhalation devices were extensively trained with the inhalation technique. In practice, therefore, when the inhalation technique is suboptimal the improved delivery to the lung from these devices should be greater.

Vidgren et $a l,{ }^{8}$ using gamma scintigraphy with technetium-99m labelled disodium cromoglycate, reported that the mean fractional lung deposition increased by $56 \%$ following inhalation with a Nebuhaler compared with the MDI. This value is similar to the $53.4 \%$ increase from this study. Greater lung deposition was also reported by Newman et al $l^{9}$ using gamma scintigraphy with technetium-99m labelled Teflon. This study revealed a $140 \%$ increase in the pulmonary deposition with the Nebuhaler compared with the MDI. A recent report ${ }^{13}$ using salbutamol labelled with technetium-99m formulated in an $\mathrm{MDI}^{14}$ has shown greater peripheral lung deposition when using a Volumatic with the MDI. In normal and asthmatic subjects the peripheral lung deposition was reported to be $12.02 \%$ and $26.97 \%$, respectively, greater using the Volumatic than the MDI on its own. The greater deposition in the volunteers could reflect their inhalation technique because the training given would have been recent. The values are similar to the $19.1 \%$ increase we have demonstrated for the Volumatic.

Similar relative bioavailabilities to the lung $(3.49 \%$ and $4.09 \%)$ were observed after inhalation with the open mouth technique and with the Bricanyl Spacer. Vidgren $e t a l^{8}$ reported a $75 \%$ greater pulmonary deposition from the Bricanyl Spacer than with the MDI, which is higher than the $44.5 \%$ obtained from this study. They also reported a total systemic availability of $56 \%$ for the Bricanyl Spacer which is also higher than the $43.8 \%$ from this study. The pulmonary deposition from the Bricanyl Spacer was not as great as that using the large volume inhalers and more was swallowed. This finding is as expected because the Bricanyl Spacer is a tube extension spacer $(80 \mathrm{ml})$ and its design affects the deposition pattern of the inhaled dose compared with the large volume spacers. The open mouth method is analogous to the tube spacer because the increased distance between the mouth and the actuator is the same. The reduced aerosol velocity of both these methods allows a time lag between actuation and inspiration. The Bricanyl Spacer provides a control for the direction of the aerosol, thus preventing acci- dental misdirection of the spray cloud (for example, into the eyes) which may occur with the open mouth method.

The increased lung deposition when MDIs are used with large volume spacer devices, especially in those with poor inhalation technique, should improve lung function. However, previous studies have reported conflicting clinical efficacy of large volume spacers. ${ }^{15-17}$ These studies were not dose ranging and did not include an assessment of each subject's inhalation technique. Although volunteers were used in this study it can be concluded that, if similar amounts of drug are deposited into the airways of the lungs, an equivalent lung function response should be obtained bioequivalence of inhaled products. ${ }^{18}$ The results when the spacers were used, however, showed that the amount deposited in the lungs increased and, therefore, the clinical significance of increased lung deposition should be investigated. Using the urinary salbutamol method it is now possible to carry out clinical studies using the patients' own inhaled products and spacers to correlate improved lung bioavailability, decreased systemic availability, and pharmacodynamic outcome (efficacy and safety), together with an identification of the inhaler technique to be used and the dose required. If the outcome of these is positive, then the approach advocated by Keeley $^{7}$ for the universal use of spacers could be adopted, rather than recommendations being restricted to children, ${ }^{19}$ elderly, and poor coordinators, ${ }^{20}$ and those taking high inhaled doses of corticosteroids. $^{21}$

The authors are grateful to all of the volunteers who took part in this study and to Mrs Frances Dawson for secretarial assistance. MH was in receipt of a Science and Engineering Research Council studentship.

1 Paterson IC, Crompton GK. Use of pressurised aerosols by asthmatic patients. BMf 1976;1:76-7.

2 Orehek J, Gayrard P, Grimaud CH, Charpin J. Patient error in the use of bronchodilator metered aerosols. $B M \mathcal{F}$ $1976 ; 1: 76$.

3 Crompton GK. Problems patients have using pressurised aerosol inhalers. Eur 7 Respir Dis 1982:63(Suppl):101-4.

4 Dolovich M, Ruffin RE, Roberts R, Newhouse MT. Optimal delivery of aerosols from metered dose inhalers. Chest 1981;80(Suppl):911-5.

5 Toogood J, Jennings B, Greenway R, Chuang L. Candidiasis and dysphonia complicating beclomethasone treatment in asthma. F Allergy Clin Immunol 1980;65:143-53.

6 Prahl P, Jensen T. Decreased adrenocortical suppression utilizing the Nebuhaler for inhalation of steroid aerosols. Clin Allergy 1987;17:393-8.

7 Keeley D. Large volume plastic spacers in asthma. $B M \mathcal{F}$ 1992;305:598-9.

8 Vidgren MT, Paronen TP, Karkkainen A, Karjalainen P. Effect of extension devices on the drug deposition form inhalation aerosols. Int $\mathcal{f}$ Pharm 1987;39:107-12.

9 Newman SP, Miller AB, Lennard-Jones TR, Moren F, Clarke SW. Improvement of pressurised aerosol deposition with a Nebuhaler spacer device. Thorax 1984;39:93541.

10 Hindle M, Chrystyn H. Determination of the relative bioavailability of salbutamol to the lung following inhalation. Br $\mathcal{F}$ Clin Pharmacol 1992;34:311-5.

11 Hindle $M$, Newton DAG, Chrystyn $H$. Investigations of an optimal inhaler technique using urinary salbutamo excretion as a measure of relative bioavailability to the lung. Thorax 1993;48:607-10.

12 Cyr TD, Graham SJ, Lik YR, Lovering ET. Low firstspray drug content in albuterol metered dose inhalers.
Pharm Res 1991;8:658-60.

13 Melchor R, Biddiscombe MF, Mak VHF, Short MD, Spiro SG. Lung deposition patterns of directly labelled salbuta$\mathrm{mol}$ in normal subjects and in patients with reversible mol in normal subjects and in patients with
airflow obstruction. Thorax 1993;48:506-11.

14 Biddiscombe MF, Melchor R, Mak VHF, Marriott RJ Short MD, Spiro SG. The lung deposition of salbutamol directly labelled with technetium-99m, delivered by pres- 
surised metered dose and dry powder inhalers. Int $f$ Pharm 1993;91:111-21.

15 Konig P. Spacer devices used with metered dose inhalers: breakthrough or gimmick? Chest 1985;88:276-84.

16 Chapman BJ, Crompton GK. Comparison of terbutaline via the Nebuhaler and salbutamol via the Volumatic theory and practice. Eur Respir $\mathcal{F} 1990 ; 3: 584-8$.

17 Munch EP, Hidinger KG, Weeke B. Bronchodilation of terbutaline in small doses from a $750 \mathrm{ml}$ spacer. Allergy 1983;38:487-91.
18 Chrystyn $H$. Standards for the bioequivalence of inhaled products. Clin Pharmacokinet 1994;6:1-6.

19 Rivlin J, Mindorff C, Reilly P, Levsion H. Pulmonary response to a bronchodilator delivered from three inhalation devices. $\mathcal{f}$ Pediatr 1984;104:470-3.

20 Bloomfield $\mathrm{P}$, Crompton GK. A tube spacer to improve inhalation of drugs from pressurised aerosols. $B M \mathcal{F}$ inhalation of drug

21 British Thoracic Society. Guidelines on the management of asthma. Thorax 1993;48(Suppl):1-24.

\section{The Crofton Cup}

British Lung Foundation ventures are astonishingly effortophilic - turning up on an October day when the Perthshire mountains are white with the first snow and hands are as blue as the sky.

Old acquaintances, friends of friends, and not a few colleagues consent to over-the-odds payment for the cause. Handicaps are cut by a cruel third under Crofton Cup rules and they're off - brisk, focused, as courteous as golfers meeting in the rough.

"How's your game?"

"Much like yours."

Off they go in their opposite ways. The longest drive is won by a lady on the uphill par 5. The 290 yard gentleman accepts defeat although the lady has the advantage of the forward tee (120 yards start).

"Bad luck."

Breathless at the green we agree that this course is not for those with compromised airflow or low transfer factor. The youngest competitor nearest the pin on the 18th was furthest away from fitting the prize - Sam T's Ryder Cup shirt - nice photograph though and signed with a pencil which has graced a thousand scorecards.

So what if Sir John denied golfing genius, his was a player's speech - crisp, precise, humorous, and gently self-critical - the ideal approach from tee to green. By sheer luck the cup was won by a chest physician domiciled in St Andrews. Did October's alternative golf attraction (Dunhill Cup) in that nearby town reduce our numbers? Maybe a courtesy bus for the golfers with emphysema went there instead.

The American Lung Association has a Golf Privilege Scheme to reduce playing fees to subscribers which was advertised in the Christmas edition of Golf Magazine as: "Some gifts are so special they take your breath away. Some gifts give it back." The monetary gifts involving tobacco sponsorship in sport seem inappropriate. The money from the good old generous cigarette manufacturer is proposed as a gift to the sport of golf which then kindly allows advertising only from the sponsor. Several questions arise. Which will survive? Will tobacco sponsorship outlive the sport? Which can breath hold longer? Can golf survive as we know it, and escape from the noose of tobacco advertising and its slow asphyxia?

The Crofton Cup and the Dunhill Cup were a happy coincidence. Blue hands again next year I suppose - or maybe not - since the Crofton Cup will be played at the end of September on a links Open qualifier course which is primed for this year's Open at Turnberry. Neither the Open nor the Crofton Cup are sponsored by tobacco - in fact, the Crofton is the main UK golf competition which extols the basic philosophy of a non-smoking golf event. Details of the next Crofton Cup can be obtained from The British Lung Foundation Scottish Office, Royal College of Physicians and Surgeons of Glasgow, 232-42 St Vincent Street, Glasgow G2 5RJ (tel: 041204 4110).

KENNETH ANDERSON 